\title{
Analysis of the Levels of Physical Activity in the Quality of Life of Elderly Patients With Hypertension
}

\author{
Leônidas Oliveira Neto ${ }^{1,2}$, Vagner Deuel de Oliveira Tavares ${ }^{2}$, \\ Ângelo Augusto Paula do Nascimento ${ }^{3} \&$ Kenio Costa Lima ${ }^{3}$ \\ ${ }^{1}$ Federal University of Rio Grande do Norte, Department of Artes, Rio Grande do Norte, Natal \\ ${ }^{2}$ Laboratory of Hormone Measurement, Department of Physiology and Behavior, Federal University of Rio \\ Grande do Norte, Natal, Brazil \\ ${ }^{3}$ Federal University of Rio Grande do Norte, Graduate Program in Collective Health, Rio Grande do Norte, Natal \\ Correspondence: Leônidas Oliveira Neto, Central Committee on Ethics in Research with Human, Federal \\ University of Rio Grande do Norte, Natal/RN, Brazil. Protocol Number: 0290.0.051.000-11, Av. Senador Salgado \\ Filho, 3000, Zip Code:59078-970, Lagoa Nova, Natal/RN, Brazil. E-mail: leonidasoliveiraneto@gmail.com
}

Received: September 25, 2019 Accepted: October 23, 2019 Online Published: March 30, 2020

doi:10.5539/gjhs.v12n4p138 URL: https://doi.org/10.5539/gjhs.v12n4p138

\begin{abstract}
Background: Changes in lifestyle are essential to promote the control of hypertension and quality of life in older adults. Objective: To verify the influence of the level of physical activity (LPA) on quality of life in hypertensive older adults.

Method: The sample included a total of 291 hypertensive older adults, 102 men and 189 women, with a mean age of $69.7 \pm 7.7$ and $69.2 \pm 7.2$ respectively. The General Linear Model was applied to measure the interactions (LPA and sex) between active and inactive groups.

Results: There was a difference between active men and active women with inactive older adults of both sexes for mental status $(\mathrm{p}<.0001)$, as well as a difference between active men and active women with inactive older adults of both sexes for somatic manifestations $(\mathrm{p}<.0001)$. No differences were observed between active men and active women for any other variables.
\end{abstract}

Conclusion: Our results suggest that a higher level of physical activity can lead to a better quality of life.

Keywords: physical activity, gender, Quality of life, health, hypertension

\section{Introduction}

Aging is an inevitable event in life, including physiological decline and a state of disease (Abrass, 1990). Systemic Arterial hypertension (SAH) is an important risk factor for cardiovascular morbidity and mortality, particularly in older adults (Pinna, Pascale, La Regina, \& Orlandini, 2012).

Studies indicate there are approximately 1.1 billion people with SAH worldwide, accounting for approximately 9.4 million deaths, resulting from complications, annually (Jones \& Hall, 2007; Perkovic, Huxley, Wu, Prabhakaran, \& MacMahon, 2007; WHO, 2013). Clinical Studies have shown that the detection, treatment, and control of SAH are fundamental for the reduction in cardiovascular events (Praxede, Lopes, \& Monego, 2006). In addition, SAH affects the quality of life, which are linked to the very existence of illness. The SAH carrier, ends up having negative effects on physical, emotional and social aspects (Carvalho, Siqueira, Sousa, \& Jardim, 2013).

Therapies used to control SAH basically include drug and non-pharmacological interventions (Gravina, Grespan, \& Borges, 2007; Perrotti et al., 2007). Among the non-pharmacological therapies, we can highlight adherence to healthy habits, such as physical exercise and food re-education, such as dietary salt restriction, and suppression of alcohol (Rondon \& Brum, 2003; Soares, Barcellos, Sclowitz, Krolow, \& Sclowitz, 2006). Thus, changes in lifestyle related to personal habits and health care, besides promoting relief of symptoms and controlling SAH, also increase the Quality of Life (QoL) of hypertensive patients (Youssef, Moubarak, \& Kamel, 2005). QoL is the perception of the individual with SAH of their position in life within the context of their culture and the system of values in which they live, as well as in relation to their goals, expectations, standards, and concerns (United Nations, 2002). QoL can be determined by the "feeling of physical well-being and emotional, psychic, and social satisfaction" (Fleck et al., 2000). 
Above all, a decreased QoL implies having impaired autonomy and independence (Kawano, Araújo, Castro, \& Matos, 2015), highlighting the importance of the search for ways to improve QoL. Studies have shown that practicing physical activity seems to be a low-cost tool (Pedersen \& Saltin, 2015), which offers a protection factor and treatment for SAH (Liu et al., 2017) and contributes to the reduction in excess body weight, which in turn also assists in the control of SAH (Jackson, Herber-Gast, \& Brown, 2014).

Thus, to the present study aimed to evaluate the QoL of older hypertensive individuals, identifying the influence of the level of physical activity (LPA) in this context, since studies on this subject are scarce.

\section{Method}

The study included older participants who were invited for social networks to a screening interview and diagnosed with hypertension by a physician or brought the medical report with a statement that he was hypertensive. In the according to the following inclusion criterion, being aged $\geq 60$ years, having systemic arterial hypertension, and not presenting the following health conditions: secondary causes of arterial hypertension; renal, cardiac or hepatic insufficiency; and patients who had recent cardiovascular events. In addition, cases of lung disease, users of alcoholic beverages or oral contraceptives, patients with disorders such as diabetes mellitus, neuropathies, autoimmune diseases, chagas disease, cardiac arrhythmias, and other diseases that affect autonomic control, as well as users of antidepressants, neuroleptics, antiarrhythmic agents, and lithium were excluded. No patient in the sample had any other comorbidities associated with hypertension, except for dyslipidemia. Finally, individuals excluded during the interview, who were unable to understand the instructions of the questionnaires.

\subsection{Participants}

All participants who met the inclusion criteria attended interviews to complete in a single day the Mini-Questionnaire on Quality of Life (MINICHAL), in to assess QoL, and the main factors that influence individuals with hypertension (Schulz, Rossignoli, Correr, Fernandez-Llimos, \& Toni, 2008), the International Physical Activity Questionnaire (IPAQ), to evaluate the measurement of the LPA (Matsudo, Araujo, Matsudo, \& Andrade, 2001). To sign the consent form under the Declaration of Helsinki, Protocol 263/11; CAAE 0290.0.051.000-11.

\subsection{International Physical Activity Questionnaire (IPAQ)}

The International Physical Activity Questionnaire (IPAQ) is a questionnaire proposed by the World Health Organization (1998), which allows estimation of the weekly time spent on physical activities, of moderate and vigorous intensity, in different contexts of daily life, such as: work, transportation, housekeeping, and leisure, and also the time spent on passive activities performed in sitting and lying positions. The 27 questions that compose the questionnaire contain response options in number of days per week and time spent on exercise or activity (hours or minutes). Through these data the individuals are classified into sedentary and physically active, using a minimum time of 150 minutes per week of physical activity as a cut-off point for physically active (Matsudo et al., 2001; Pardini et al., 2001).

\subsection{MINICHAL}

The MINICHAL Questionnaire contains 16 multiple-choice questions organized in two factors: Mental State (10 questions), Somatic Manifestations (6 questions), and a question to verify how the patient considers that their hypertension and its treatment influence their QoL. The patient is required to answer the questions referring to the previous seven days. The responses of the domains are distributed on a Likert-type frequency scale and have four response options of 0 (No, absolutely not) to 3 (Yes, a lot). The maximum score for the Mental State is 30 points, and for the Somatic Manifestations, 18 points. On this scale, results closer to 0, considering the set of questions, represent a better QoL. Question 17, which evaluates the general perception of the patient's health, is scored on the same Likert scale, but is not included in either of the two domains. In the analysis of the internal consistency, the Brazilian version of the MINICHAL presented Cronbach's Alpha values of 0.88 for the domain Mental State and 0.86 for Somatic Manifestations. Evaluation of the content validity analysis showed a high agreement rate (75.44\%). The factorial analysis confirmed the two factors, with differences in one item, which was included in Factor 2. The control group showed significant differences with respect to hypertension $\mathrm{t}=4,86, \mathrm{gl}=276,8, \mathrm{p}<$ 0.001 (Schulz et al., 2008).

\subsection{Statistical Analysis}

The sample size calculation was stipulated according to the number of hypertensive and diabetic patients presented in the Registration and Monitoring of Hypertensive and diabetics (HIPERDIA-DATASUS), in the year 2011, considering a level of confidence of $95 \%$, to avoid a type 2 sampling error using statistical power analyses 
(Gpower 3.1). The population of patients with hypertension was 189 individuals for women and 102 individuals for men. Thus, the number of subjects for the present study was required to include 96 men and 179 women, aged 60 years or above, with a medical diagnosis of SAH or classified as hypertensive, according to the VII Brazilian Guidelines for Arterial Hypertension (Brazilian Society of Cardiology, 2016)

The normality of the data was verified by the Kolmogorov-Smirnov test. The data are expressed as mean and ( \pm ) standard deviation, as well as in absolute (n) and relative (\%) frequencies. The Chi-square Test was used to compare the frequencies (\%) of men and women between active and sedentary groups. A General Linear Model (GLM) followed by the Bonferroni post hoc test was used to evaluate the interaction effect of independent variables (sex and LPA) on the dependent variables of the MINICHAL questionnaire. Cohen $d$ was used as a measure of the effect size (ES) for pairwise comparisons and interpreted as follows: trivial $(<0.2)$, small $(0.2$ to 0.5 ), moderate ( 0.6 to 1.1$)$, large (1.2 to 1.9$)$, very large (2.0 to 3.9$)$, and nearly perfect ( $\geq 4.0)$. Statistical significance was set at $\mathrm{p}<0.05$ and was used d-cohen for power analysis. We performed odds ratios (ORs) with $95 \%$ confidence interval (CI) were estimated for multivariate models in the overall sample. The data were analyzed using the software Statistical Package for the Social Sciences (SPSS) 18.0, adopting a significance level of 5\% (P $<0.05)$.

\section{Results}

The present study included a sample of 291 older adults, with a clinical diagnosis of systemic arterial hypertension, of which; $59.8 \%$ of women were physically active and $40.2 \%$ sedentary, and, in relation to men, $52.0 \%$ were physically active and $48.0 \%$ sedentary. Moreover, after analyzing the frequency of the LPA and the classification into active and sedentary groups between men and women, it was found that there was no prevalence $(p>0.05)$ of one profile over the other (Table 1).

All results are described as Mean Difference (MD) between groups and sexes. Table 2 shows a difference between active men with sedentary men (MD -4.15) and sedentary women (MD -3.08) for education $(\mathrm{P}<.0001)$; and between active women with sedentary men (MD-1.78) and sedentary women (MD-2.86) for education $(\mathrm{P}<.0001)$.

Table 1. Characterization of the sample of older hypertensive patients. Data expressed as mean and standard deviation $( \pm)$

\begin{tabular}{lllllll}
\hline & $\begin{array}{l}\text { ACTM } \\
(\mathbf{n}=\mathbf{5 3})\end{array}$ & ICTM (n=49) & (d) & $\begin{array}{l}\text { ACTW } \\
(\mathbf{n}=\mathbf{1 1 3})\end{array}$ & $\begin{array}{l}\text { ICTW } \\
(\mathbf{n}=\mathbf{7 6})\end{array}$ & (d) \\
\hline Age (yrs) & $68.4 \pm 7.0$ & $71.3 \pm 8.2$ & 0.38 & $68.6 \pm 7.3$ & $70.1 \pm 7.2$ & 0.20 \\
Education (yrs) & $9.0 \pm 5.3 \# \dagger$ & $4.8 \pm 3.1$ & 0.96 & $7.3 \pm 4.5 \# \dagger$ & $5.9 \pm 4.3$ & 0.31 \\
\hline
\end{tabular}

Note $(\mathrm{d})=\mathrm{d}$-cohen; ACTM = Active men; ICTM = Inactive Men; ACTW = Active women; ICTW = Inactive women; \# = p $<$ 0.05 compared to sedentary men; $\uparrow=\mathrm{p}<0.05$ sedentary women.

All results are described as Mean Difference (MD) between groups and sexes. Differences were observed between active men with sedentary men (MD -12.3) and sedentary women (MD -12.4) for mental status ( $<.0001)$; between active women with sedentary men (MD -11.8) and sedentary women (MD -11.6) for mental status $(\mathrm{p}<.0001)$; between active men with sedentary men (MD -9.19) and sedentary women (MD -9.63) for somatic manifestations $(\mathrm{p}<.0001)$; and between active women with sedentary men (MD -8.58) and sedentary women (MD -9.02) for somatic manifestations $(\mathrm{p}<.0001)$. Differences were found only between active men and sedentary men (MD -1.28), and between active women and sedentary men (MD -1.34) for the perception of quality of life $(\mathrm{p}<.0001)$. There were no differences between active men and active women for any other variables. 
Table 2. Comparison of active and sedentary groups among older hypertensive men and women older adults on the level of health-related quality of life according to the quality of life questionnaire: MINICHAL. Data expressed as mean and standard deviation $( \pm)$

\begin{tabular}{lllllll}
\hline & $\begin{array}{l}\text { ACTM } \\
(\mathbf{n}=\mathbf{5 3})\end{array}$ & $\begin{array}{l}\text { ICTM } \\
(\mathbf{n = 4 9 )}\end{array}$ & $\mathbf{( d )}$ & $\begin{array}{l}\text { ACTW } \\
(\mathbf{n = 1 1 3})\end{array}$ & $\begin{array}{l}\text { ICTW } \\
(\mathbf{n = 7 6})\end{array}$ & (d) \\
\hline Mental status (score) & $1.9 \pm 2.2 \# \dagger$ & $14.2 \pm 6.5$ & 2.53 & $2.5 \pm 3.3 \dagger$ & $14.4 \pm 5.6$ & 2.58 \\
SOMANI (score) & $1.3 \pm 1.9 \# \dagger$ & $10.5 \pm 4.7$ & 2.56 & $1.9 \pm 2.3 \# \dagger$ & $11.0 \pm 5.8$ & 2.06 \\
Perceived QoL (score) & $0.5 \pm 0.8 \#$ & $1.8 \pm 4.7$ & 0.38 & $0.5 \pm 0.7 \#$ & $1.2 \pm 1.2$ & 0.71 \\
\hline
\end{tabular}

Note. $(\mathrm{d})=\mathrm{d}$-cohen; QoL - quality of life. SOMANI - Somatic Manifestations; ACTM = Active men; ICTM = Inactive Men; ACTW = Active women; ICTW = Inactive women; $\#=p<0.05$ compared to sedentary men; $\uparrow=\mathrm{p}<0.05$ sedentary women.

Table 3. Logistic regression with variance for ratios of prevalence levels of physical activity in relation to mental status, SOMANI and Perceived QoL

\begin{tabular}{llllll}
\hline LPA & $\boldsymbol{\beta}$ & $\begin{array}{l}\text { Standard } \\
\text { error }\end{array}$ & OR & p-value & $\begin{array}{l}\text { Confidence Interval } \\
\mathbf{( 9 5 \% )}\end{array}$ \\
\hline Mental status (score) & .254 & .080 & 1.29 & $0.002 *$ & $1.11-1.51$ \\
SOMANI (score) & .197 & .122 & 1.21 & 0.107 & $0.95-1.54$ \\
Perceived QoL (score) & .056 & .120 & 1.05 & 0.639 & $0.83-1.33$ \\
\hline
\end{tabular}

Note. LPA- Levels of physical activity; QoL - quality of life. SOMANI - Somatic Manifestations.

\section{Discussion}

The present study aimed to analyze the influence of the level of physical activity on the health-related quality of life of older adults with SAH. It was observed that a good mental state, somatic manifestations, and perception of quality of life are intimately linked to the practice of physical activity. Our study identified that active older adults have a higher education level when compared to sedentary individuals. In addition, was identified that mental status was associated with physically active.

Older individuals who are active have a higher number of education years, and these data are consistent with the research performed by (Reis \& Glashan, 2005). In that study, one of the factors used to explain this point is that individuals with a better level of knowledge also understand better their pathology and the severity, which can influence the pursuit of a better quality of life. A result similar to this was obtained in another study (Sprangers et al., 2000) which showed that factors such as the level of education are related to low levels of quality of life, that is, the older with a higher degree of education obtained more satisfactory results in the MINICHAL questionnaire. Thus, when factors such as sedentarism and lower educational level are related, the individuals seem to present a worse quality of life assessment (Barroso, Jardim, Vitorino, Bittencourt, \& Miquetichuc, 2008; Mota, Ribeiro, Carvallho, \& Matos, 2006). Therefore, keeping active in physical activity can be a tool for school development (Hillman, Erickson, \& Kramer, 2008).

The mental state measured by the MINICHAL questionnaire identifies whether the individual presents problems with sleep, social relations, life usefulness, decision making, anxiety, and physical exhaustion (Côrtes, Arantes, Mendonça, \& Silva, 2007). Our study found that older active men possess a better mental state than sedentary men and sedentary women. However, it does not differentiate between active men and women. In addition, we result support that physical active can benefit mental state and has a chance ratio is 1.2 times higher for active individuals. Mental state is essential for daily tasks and provides a better quality of life (Bezerra \& Veiga, 2013). Thus, we recognize the influence of the practice of physical activity on the mental state. Physical activity directly benefits brain regions responsible for the control of anxiety and resolutions of problems, which directly influence the mental state (Parker et al., 2016). In this way, a greater level of activity is required to benefit the mental state.

Another variable of our study was somatic manifestations, which represent the sums of perceptions about the body, specifically on health, of how hypertension hinders daily life (Melchiors et al., 2009). We found that the active older adults, when compared to sedentary individuals, of both sexes, presented fewer somatic symptoms. Thus, being active is closely related to physical activity to promote an improvement in body perception (Andrade, Junior, 
Capelari, \& Vieira, 2012; Benedetti, Físicos, \& Idosos, 2003) in hypertensive older adults.

Therefore, the finding that active older men obtained better QoL scores than the sedentary older of both sexes, similarly occurred for active older women, who presented better QoL scores when compared to sedentary older men and women. Sedentary older adults obtained higher values than the older practicing physical activities in different domains in the MINICHAL, such as mental state, somatic manifestations, and the perception of quality of life related to health. Our results suggest that being active improves the quality of life in the domains of "mental status", "somatic manifestations", and "perception of quality of life related to the disease". Thus, being active benefits physical health, and, as a consequence, improves the quality of life of hypertensive older adults.

Regarding the limitations of our study and some points that would be interesting for more complete data collection, we mention the drug profile used and anthropometric measurements, which would allow deepening of the results. It is also essential to perform new research with groups of individuals with pulmonary arterial hypertension.

Knowledge of the benefits of the practice of physical activities could be an important factor for development and adherence (Prado, Mamede, Almeida, \& Clapis, 2004). For this reason, for older adults to have a good quality of life it is important for them to perform physical activities, which promote a delay in the physiological changes of aging and promote well-being (Gómez-Morales et al., 2019).

\section{Conclusion}

In conclusion, older hypertensive patients of both sexes (men and women) present similar frequencies of physically active and sedentary individuals. Physically active older adults with SAH present a higher level of education and better QoL than their sedentary peers.

\section{Acknowledgments}

This study was financed in part by the Coordenação de Aperfeiçoamento de Pessoal de Nível Superior - Brasil (CAPES) - Finance Code 001

\section{Competing Interests Statement}

The authors declare that there are no competing or potential conflicts of interest.

\section{References}

Abrass, I. B. (1990). The biology and physiology of aging. The Western Journal of Medicine, 153(6), 641-645. https://doi.org/2293470

Andrade, J. R., Junior, N., Capelari, J. B., \& Vieira, L. F. (2012). Impact of Physical Activity on Perceived Stress and Life Satisfaction of Elderly People. Rev. Educ. Fis/UEM, 23(4), 647-654. https://doi.org/10.4025/reveducfis.v23.4.16934

Barroso, W. K. S., Jardim, P. C. B. V., Vitorino, P. V., Bittencourt, A., \& Miquetichuc, F. (2008). Influência da atividade física programada na pressão arterial de idosos hipertensos sob tratamento não-farmacológico. Revista Da Associação Médica Brasileira, 54(4). https://doi.org/10.1590/s0104-42302008000400018

Benedetti, T. B., Físicos, E., \& Idosos, A. E. A. E. M. (2003). EXERCISE ACTIVITY AND SELF-IMAGE / SELF-ESTEEM IN NURSING HOME RESIDENTS. Revista Brasileira de Cineantropometria e Desempenho Humano, (December). https://doi.org/1980-0037

Bezerra, S., \& Veiga, E. (2013). Qualidade de vida entre pessoas com hipertensão arterial atendidos em unidades de estratégias de saúde da família. Rev Enf UFPE on Line, 7(esp), 7055-7063. https://doi.org/10.5205/reuol.4767-42136-1-ED.0712esp201313

Brazilian Society of Cardiology (BSC). (2016). 7th Brazilian Guidelines of Hypertension. Arquivos Brasileiros de Cardiologia, 107(3), 1-83. https://doi.org/0066-782X

Carvalho, M. V. de, Siqueira, L. B., Sousa, A. L. L., \& Jardim, P. C. B. V. (2013). The Influence of Hypertension on Quality of Life. Arquivos Brasileiros de Cardiologia, 100(2), 164-174. https://doi.org/10.5935/abc.20130030

Côrtes, D. C. de S., Arantes, A. A., Mendonça, A. P. P., \& Silva, J. dos S. (2007). Quality of Life and Hypertension. Rev. Psiq. Clin, 34(1), 105-115. https://doi.org/10.5935/2359-4802.20170002

Fleck, M. P., Louzada, S., Xavier, M., Chachamovich, E., Vieira, G., Santos, L., \& Pinzon, V. (2000). Application of the Portuguese version of the abbreviated instrument of quality life WHOQOL-bref. Revista de Saúde Pública, 34(2), 178-183. https://doi.org/10.1590/S0034-89102000000200012

Gómez-Morales, A., Miranda, J. M. A. de, Pergola-Marconato, A. M., Mansano-Schlosser, T. C., Mendes, F. R. P., 
\& Torres, G. de V. (2019). The influence of activities on the quality of life of the elderly: a systematic review. Ciência \& Saúde Coletiva, 24(1), 189-202. https://doi.org/10.1590/1413-81232018241.05452017

Gravina, C. F., Grespan, S. M., \& Borges, J. L. (2007). Non-pharmacological treatment of hypertension in the elderly. Rev Bras Hipertens, 14(1), 33-36.

Hillman, C. H., Erickson, K. I., \& Kramer, A. F. (2008). Be smart, exercise your heart: exercise effects on brain and cognition. Nature Neuroscience, 9(1), 58-65. https://doi.org/10.1038/nrn2298

Jackson, C., Herber-Gast, G.-C., \& Brown, W. (2014). Joint Effects of Physical Activity and BMI on Risk of Hypertension in Women: A Longitudinal Study. Journal of Obesity, 2014, 1-7. https://doi.org/10.1155/2014/271532

Jones, D. W., \& Hall, J. E. (2007). World Hypertension Day 2007. Hypertension, 49(5), 939-940. https://doi.org/10.1161/hypertensionaha.107.088740

Kawano, M. M., Araújo, I. L. A., Castro, M. C., \& Matos, M. A. (2015). Assessment of quality of life in patients

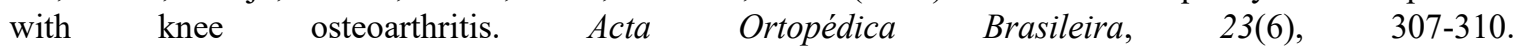
https://doi.org/10.1590/1413-785220152306150596

Liu, X., Zhang, D., Liu, Y., Sun, X., Han, C., Wang, B., .. Zhang, M. (2017). Dose-Response Association between Physical Activity and Incident Hypertension: A Systematic Review and Meta-Analysis of Cohort Studies. Hypertension, 69(5), 813-820. https://doi.org/10.1161/HYPERTENSIONAHA.116.08994

Matsudo, S., Araujo, T., Matsudo, V., \& Andrade, D. (2001). Physical activity questionnaire (lpaq): study of validity and reliability in brazil. Atividade Física \& Saúde, 6(2). https://doi.org/10.12820/rbafs.v.6n2p5-18

Melchiors, A. C., Correr, C. J., Pontarolo, R., Oliveira, F. De, Santos, D. S., Augusto, R., \& Paula, D. (2009). Quality of Life in Hypertensive Patients and Concurrent Validity of Minichal-Brazil. Brazilian Society Cardiology, 337-344. https://doi.org/10.1590/S0066-782X2010000300013

Mota, J., Ribeiro, J. L., Carvallho, J., \& Matos, M. G. (2006). Atividade física e qualidade de vida associada à saúde em idosos participantes e não participantes em programas regulares de atividade física. Rev Bras Educ Fis, 20(3), 219-225. https://doi.org/10.1590/S1807-55092006000300007

Pardini, R., Matsudo, S., Araújo, T., Matsudo, V., Andrade, E., Braggion, G., ... Raso, V. (2001). Validação do questionário internacional de nível de atividade física (IPAQ-versão 6): estudo piloto em adultos jovens brasileiros Validation of the International Physical Activity Questionaire (IPAQ version 6): pilot study in Brazilian young adults, 45-51. https://doi.org/10.1590/S1980-00372010000600013

Parker, A. G., Hetrick, S. E., Jorm, A. F., Mackinnon, A. J., McGorry, P. D., Yung, A. R., ... Purcell, R. (2016). The effectiveness of simple psychological and physical activity interventions for high prevalence mental health problems in young people: A factorial randomised controlled trial. Journal of Affective Disorders (Vol. 196). Elsevier. https://doi.org/10.1016/j.jad.2016.02.043

Pedersen, B. K., \& Saltin, B. (2015). Exercise as medicine - Evidence for prescribing exercise as therapy in 26 different chronic diseases. Scandinavian Journal of Medicine and Science in Sports, 25, 1-72. https://doi.org/10.1111/sms.12581

Perkovic, V., Huxley, R., Wu, Y., Prabhakaran, D., \& MacMahon, S. (2007). The Burden of Blood $\begin{array}{llll}\text { Pressure-Related } \quad \text { Disease. } & \text { Hypertension, }\end{array}$ https://doi.org/10.1161/HYPERTENSIONAHA.107.095497

Perrotti, T. C., Filho, J. C., Uehara, C. A., Mello, C. De, Filho, A., \& Miranda, R. D. (2007). Tratamento farmacológico da hipertensão no idoso. Revista Brasileira de Hipertensão, 14(1), 37-41.

Pinna, G., Pascale, C., La Regina, M., \& Orlandini, F. (2012). Hypertension in the elderly. Italian Journal of Medicine, 6(4), 285-294. https://doi.org/10.1016/j.itjm.2012.02.003

Prado, M. A. S., Mamede, M. V., Almeida, A. M. de, \& Clapis, M. J. (2004). A Prática Da Atividade Física Em Mulheres Submetidas À Cirurgia Por Câncer De Mama. Percepção De Barreiras E Benefícios, 12(3), 494-502. https://doi.org/10.1590/S0104-11692004000300007

Praxedes C. E., Lopes, H ., Monego, E. T., \& J. N. , N. (2006). V Diretrizes Brasileiras De Hipertensão Arterial. Revista Brasileira de Hipertensão, 13, 277-280. https://doi.org/10.1590/S0066-782X2007001500012

Reis, M. G. dos, \& Glashan, R. de Q. (2005). Adultos hipertensos hospitalizados: percepção de gravidade da doença e de qualidade de vida. Revista Latino-Americana de Enfermagem, 9(3), 51-57. 
https://doi.org/10.1590/s0104-11692001000300008

Rondon, M., \& Brum, P. C. (2003). Exercício físico como tratamento não farmacológico da hipertensão arterial. Revista Brasileira de Hipertensão, 10(11), 134-139.

Schulz, R. B., Rossignoli, P., Correr, C. J., Fernandez-Llimos, F., \& Toni, P. M. De. (2008). Validation of the short form of the spanish hypertension quality of life questionnaire (MINICHAL) for Portuguese (Brazil). Arquivos Brasileiros de Cardiologia, 90(2), 127-144. https://doi.org/10.1590/S0066-782X2008000200010

Soares, J., Barcellos, F. C., Sclowitz, M. L., Krolow, I., \& Sclowitz, T. (2006). Hypertension Prevalence and its Associated Risk Factors in Adults : a Population-Based Study in Pelotas. Arquivos Brasileiros de Cardiologia, 54-59. https://doi.org/10.1590/S0066-782X2007000100010

Sprangers, M. A. G., Andries, F., Bijl, R. V, Foets, M., Hoeymans, N., Jacobs, A. E., .. Tijhuis, M. A. R. (2000). Which chronic conditions are associated with better or poorer quality of life? Journal of Clinical Epidemiology, 53, 895-907. https://doi.org/10.1016/S0895-4356(00)00204-3

United Nations. (2002). Political Declaration and Madrid International Plan of Action on Ageing, 2002. United Nations Publication, 49. https://doi.org/92-1-130221-8

WHO. (2013). A global brief on Hypertension World Health. World Health Organization, 1-40.

Youssef, R. M., Moubarak, I. I., \& Kamel, M. I. (2005). Factors affecting the quality of life of hypertensive patients. Eastern Mediterranean Health Journal, 11(1-2), 109-118. https://doi.org/16532679

\section{Copyrights}

Copyright for this article is retained by the author(s), with first publication rights granted to the journal.

This is an open-access article distributed under the terms and conditions of the Creative Commons Attribution license (http://creativecommons.org/licenses/by/4.0/). 